\title{
The growth of lexical constraints on spoken word recognition
}

\author{
AMANDA C. WALLEY \\ University of Alabama, Birmingham, Alabama \\ and \\ JAMIE L. METSALA \\ Ontario Institute for Studies in Education, Toronto, Ontario
}

\begin{abstract}
In this study, we examined the influence of various sources of constraint on spoken word recognition in a mispronunciation-detection task. Five- and 8-year-olds and adults were presented with words (intact or with word-initial or noninitial errors) from three different age-of-acquisition categories. "Intact" and "mispronounced" responses were collected for isolated words with or without a picture referent (Experiment 1) and for words in constraining or unconstraining sentences (Experiment 2). Some evidence for differential attention to word-initial as opposed to noninitial acoustic-phonetic information (and thus the influence of sequential lexical constraints on recognition) was apparent in young children's and adults' response criteria and in older children's and adults' reaction times. A more marked finding, however, was the variation in subjects' performance, according to several measures, with age and lexical familiarity (defined according to adults' subjective age-of-acquisition estimates). Children's strategies for responding to familiar and unfamiliar words in different contexts are discussed.
\end{abstract}

In the present study, we sought evidence bearing on the growth of lexical knowledge and the constraining influence of such knowledge on children's recognition of spoken words. By recognition, we refer to the processes involved in matching acoustic-phonetic information in the speech waveform to lexical patterns stored in memory, and we thus distinguish between these processes and those involved in lexical access (i.e., the processes by which information about words stored in the lexicon is subsequently retrieved; for further discussion, see Pisoni \& Luce, 1987). A major source of empirical evidence for lexical constraint on adult recognition has been the observation of differential responding to word-initial as opposed to noninitial acoustic-phonetic input. For example, adults accurately repeat words with first-syllable errors, but restore words with second- or third-syllable errors to their original, correct form (Bagley, 1900; Marslen-Wilson \& Welsh, 1978; see also Samuel, 1981). In addition, adults detect word-initial as opposed to noninitial phoneme targets and mispronunciations more accurately and/or slowly (Cole, 1973; Cole \& Jakimik, 1978; Cole, Jakimik, \&

This research was supported by National Sciences and Engineering Research Council Grant A1078 and a grant from the Connaught Fund, University of Toronto. A preliminary presentation of the research reported here was made at the Biennial Meeting of the Society for Research in Child Development, Baltimore, Maryland, April, 1987. We thank D. Creelman and L. Smith for suggestions concerning the analyses reported here and an anonymous reviewer for comments on an earlier version of this paper. Correspondence and requests for reprints should be sent to Amanda C. Walley, Department of Psychology, University of Alabama at Birmingham, Birmingham, AL 35294.
Cooper, 1978; Cole \& Perfetti, 1980; Jakimik, 1980; Marslen-Wilson, 1987; Marslen-Wilson \& Welsh, 1978). Furthermore, adults are better able to identify words given only word-initial, as opposed to word-final, information (Nooteboom, 1981; Salasoo \& Pisoni, 1985; Walley, 1988). On the basis of such findings, spoken word recognition has been characterized as primarily sequential, in that its component procedures involve matches between partial (vs. complete) acoustic-phonetic input and lexical representations in memory, with early, word-initial input typically constraining the processing of subsequent input (e.g., see Cole \& Jakimik, 1980; Marslen-Wilson, 1984).

Sequential recognition effects have been attributed to both structural and processing factors: At least in some languages, such as English, word beginnings are phonotactically more constrained, and thus more predictive of the identity of other segments, than are word endings (e.g., see Cole \& Jakimik, 1980; Nooteboom, 1981); in addition, because the speech signal is temporally distributed and transient, recognition processes may be initiated early and proceed largely on the basis of partial, word-initial input in order to prevent information loss (see Marslen-Wilson, 1984, 1987). Although adults' processing of word-initial input is facilitated by the availability and extent of extralexical constraints (Cole \& Jakimik, 1980; Grosjean, 1980; Salasoo \& Pisoni, 1985), it is, for present purposes, important to note that sequential recognition effects reflect the integration of bottom-up, sensory input and existing-minimally, lexical-knowledge. Thus, sequential effects have been observed for words, even those presented in isolation, but not for nonwords (Bagley, 
1900; Grosjean, 1985; Jakimik, 1980; Marslen-Wilson, 1984; Nooteboom, 1981; Salasoo \& Pisoni, 1985; Samuel, 1981; Walley, 1988).

Age-related differences in lexical knowledge therefore provide a primary theoretical basis for expecting that sequential effects do not invariantly characterize spoken word recognition throughout development. Specifically, many lexical items must differ across developmental level in familiarity-for example, by virtue of differences in age of acquisition, length of residence in memory, and/or experienced frequency. In addition, the lexicon of the young child, even at 5 or 6 years of age, is much smaller than the adult's and is still growing at a substantial rate (Miller, 1977; M. E. Smith, 1926; M. K. Smith, 1941). Therefore, particular word beginnings should not be as predictive of subsequent segments, and thus of word identity, for children as they are for adults. Consequently, the less mature/experienced system may tend not to initiate recognition procedures and/or make lexical commitments on the basis of early, word-initial acoustic-phonetic input, but may instead require more input to discriminate among lexical alternatives (see also Cole \& Perfetti, 1980). Furthermore, although young listeners are, like older ones, faced with the problem of interpreting a complex, transient signal, overall slower execution of recognition processes might necessarily result in the encoding of more acoustic-phonetic input. Apparently simple developmental differences, then, in lexical knowledge and processing could dictate that younger listeners receive a complete rather than a partial acoustic-phonetic specification of a word and thus recognize spoken words in a way that is fundamentally different from the way that adults do.

The empirical evidence bearing on sequential recognition in children is not extensive. Structural analyses indicate that a given lexical item differentiates itself from other words with similar beginnings on a "left-to-right" basis earlier (on the basis of fewer segments) in the smaller lexicons of 5- and 7-year-old children than in the adult lexicon (Charles-Luce \& Luce, in press). However, the available perceptual evidence indicates the opposite developmental trend. In gating tasks, where listeners are presented with successively greater amounts of acoustic-phonetic input corresponding to a word, 5- to 7-year-olds generally require more partial input than adults do to identify isolated, unconstrained words, and they may be less able to make use of positional information as a cue to word identity (Elliott, Hammer, \& Evan, 1987; Walley, 1988). In mispronunciation-detection tasks, 4- and 5-year-olds have been found to be equally sensitive to word-initial and -final errors in isolated, unconstrained words and thus appear to attend to information throughout such words; however, for isolated, constrained words, 5-year-olds show greater sensitivity to word-initial than to word-final errors (Walley, 1987). Young children have also been found to display differential sensitivity to word-initial input for words presented in constraining and/or familiar story contexts (Cole, 1981; Walley, 1987). Therefore, at least where contex- tual constraints are available to suggest word identity, children's recognition more closely resembles adults' (see also Tyler \& Marslen-Wilson, 1981); where such constraints are absent, however, young children's lexical knowledge may not be sufficient to support sequential recognition. Generally consistent with this proposal is work indicating that children's sentence processing may be dominated by semantic factors (e.g., Cole \& Perfetti, 1980; Tyler \& Marslen-Wilson, 1976; see also Stanovich, 1981).

In none of the aforementioned studies, however, have developmental differences in sequential word recognition, where observed, been directly tied to differences in lexical knowledge-for example, in the familiarity of lexical items or vocabulary size. (In fact, in developmental studies of spoken language processing, very little attention has generally been paid to the effects of word familiarity in terms of any measure.) In the present study, we sought evidence for such a relation by presenting young and older children and adults with words (intact, or with word-initial or noninitial mispronunciations) that varied in familiarity. "Intact" and "mispronounced" judgments were collected for isolated words presented with or without a picture referent (Experiment 1) and for words presented in constraining or unconstraining sentences (Experiment 2). The major question was whether or not lexical familiarity would be sufficient to constrain word identity at these different ages. If so, then even for our youngest subjects, we might expect to observe superior performance for the detection of initial as opposed to noninitial errors in familiar words-independent of context. Alternatively, such differential responding might only be apparent in contextually constraining situations.

Two additional concerns in the present study are related to methodological aspects of the mispronunciationdetection task. First, the central assumption with respect to this task has been that in order to detect a mispronunciation, the listener recognizes the intended word and subsequently notes the acoustic mismatch; alternatively, the listener may fail to make sense of the input and respond "mispronounced" - a relatively rare occurrence in the case of adults (Cole, 1973; Cole \& Jakimik, 1980; Cole et al., 1978). (Minimally, then, the task measures the early pattern-recognition processes that precede lexical access. $\left.{ }^{1}\right)$ However, in previous studies in which this task has been employed with children, the contribution of errors, including false alarms, to detection performance has received little attention (Cole, 1981; Cole \& Perfetti, 1980). Walley (1987), like Cole and Perfetti, did observe low false alarm rates (responses of "mispronounced," when no mispronunciation occurred) for 4- and 5-yearolds; nevertheless, false alarms varied with age and word length, and thus, perhaps, with word familiarity (see Baker, 1985b). Therefore, systematic study of how detection responses (including incorrect ones) are influenced by various stimulus and/or listener characteristics is essential for establishing the validity of the task, and it should illuminate the development of spoken word recognition. Furthermore, by examining responses to intact 
control words, we can assess how listeners' response biases for, as well as their sensitivity to, lexical information vary with age, lexical familiarity, and extralexical context-something that has not been done in previous studies in which this task has been employed.

Our second concern was with the measurement of listeners' reaction times in the mispronunciation-detection task. In previous studies, adults have been found to be more accurate at detecting word-initial rather than noninitial errors, which suggests that they attend more closely to word-initial input and do not give an extensive perceptual analysis to subsequent input (Cole, 1973, 1981; Cole et al., 1978; Marslen-Wilson \& Welsh, 1978). More typically, adult listeners are equally accurate, but slower at detecting initial as opposed to noninitial errors (Cole, 1973; Cole \& Jakimik, 1978; Cole \& Perfetti, 1980; Jakimik, 1980). That is, given incorrect word-initial input, erroneous hypotheses about word identity are formed and additional input is necessary to note the mispronunciation; in contrast, given correct word-initial input (and any preceding context), listeners begin accessing the intended word and can quickly note any mismatch between phonological expectations and subsequent input. This has been the standard account of reaction time results in the mispronunciation-detection task (e.g., Cole \& Jakimik, 1980; Jakimik, 1980), and these results have formed a large part of the empirical basis for claims concerning the constraining influence of partial, word-initial input in spoken word recognition.

There is, however, a problem with this account-one that does not appear to have been acknowledged previously. Although the observed differences in reaction times across word position in the mispronunciation-detection task might reflect differential processing of word-initial as opposed to noninitial input, they might be artifactual. Specifically, if the listener waits until stimulus offset (until all acoustic-phonetic information corresponding to a word is presented) before responding in the task, the difference might reflect the fact that reaction time measurement, which is from the onset of mispronounced segments, begins at a later point in the case of noninitial than it does in the case of initial errors. In the face of this problem, the preferred interpretation might be supported by comparison of absolute reaction times and stimulus durations and/or by the observation of interactions between the positional manipulation and other factors. ${ }^{2}$ In the present study, we adopted a simpler approach-namely, we chose to analyze reaction times for initial and noninitial mispronunciation detections separately and to make only indirect inferences about sequential recognition with this dependent measure.

\section{EXPERIMENT 1}

The results of previous developmental studies involving the mispronunciation-detection task indicate that young children, like adults, are more accurate at detecting wordinitial than they are at detecting noninitial errors and may therefore access words from their initial elements and not devote as much attention to subsequent acoustic-phonetic input (Cole, 1981; Walley, 1987). In contrast, Cole and Perfetti (1980) report no differences in detection accuracy for mispronunciations across word position for either children-including kindergarteners and preschoolersor adults. They also failed to observe any reaction time advantage for the detection of second-syllable errors over word-initial ones in either predictable or unpredictable story contexts by grade school children, but they did observe such an advantage for adults' performance. Therefore, these researchers concluded that, in comparison with adults, young listeners may defer lexical access, even in constrained contexts, until a substantially greater amount of acoustic-phonetic information has been heard. However, as suggested earlier, contextual constraint may be particularly important in determining whether children are able to rely on partial, word-initial acoustic-phonetic input for recognition; perhaps Cole and Perfetti's materials were simply not constraining enough to support such recognition. ${ }^{3}$ Cole and Perfetti also assessed the effect of the position of a mispronunciation by comparing reaction times for detecting errors in words that differed in number of syllables. Therefore, the absence of a position effect on children's reaction times might reflect differential familiarity and/or use of capacity resources in processing words of different length (e.g., see Baker, 1985b; Gibson \& Levin, 1975). Any straightforward conclusion concerning the different pattern of reaction time results observed for children and adults by Cole and Perfetti is further complicated by the measurement problem described earlier.

An additional limitation of these and other previous studies of children's recognition of spoken words is that the influence of lexical familiarity has not been extensively investigated. Considerable attention has been directed toward the importance of relevant variables, particularly word frequency, for adult recognition in both the auditory and visual domains (see, e.g., Luce, 1986); yet seldom in developmental studies has familiarity, in terms of any measure, been systematically manipulated or controlled, and we therefore know little about how it affects children's recognition or how familiarity effects emerge with development. In the research on adult recognition, estimates of the frequency of word exposure and usage have typically been based on frequency counts for written materials, such as Kučera and Francis (1967) and Thorndike and Lorge (1944). Analogous juvenile frequency norms do exist, such as Kolson (1960) and Rinsland (1945), which are based on children's spoken and written productions, as well as grade norms for children's reading vocabulary (e.g., Carroll, Davies, \& Richman, 1971; Dale \& Chall, 1948). However, these norms may underestimate the receptive vocabulary knowledge of young, preliterate children for spoken words. It has been suggested as well that adult frequency counts at least may be subject to various sampling biases (e.g., see Carroll, 1971; Lachman, Shaffer, \& Hennrikus, 1974). 
Indeed, a substantial amount of work indicates that subjective measures, such as adults' estimations of word frequency, number of meanings, and age of acquisition, are significant and often better predictors of performance in a variety of word recognition and retrieval tasks than are traditional, "objective"' measures (e.g., Carroll, 1971; Carroll \& White, 1973a, 1973b; Cirrin, 1983, 1984; Dunlap, 1980; Gilhooly \& Logie, 1981; Lachman et al., 1974; Loftes \& Suppes, 1972; Rubin, 1980).

The relative importance of these different subjective measures, in terms of their independent contributions to variations in performance, may be difficult to determine, according to Lachman et al. (1974), and may depend on such factors as subjects' age, task and stimulus characteristics, and stimulus sampling procedures (see also Cirrin, 1983, 1984; Gilhooly \& Watson, 1981). Nonetheless, ageof-acquisition estimates have perhaps received the most attention. Typically, the focus has been on this measure as a predictor of adult performance, its relation to other variables, and theoretical accounts of what it reflects, with less attention having been given to its relation to children's verbal performance. However, validation studies of adults' age-of-acquisition estimates have included examination of children's knowledge of prerated words; when adults estimate words to have been acquired around a certain age, then, indeed, children at that age respond correctly to those words in vocabulary definition and picturelabeling tasks (Gilhooly \& Gilhooly, 1980; Lyons, Teer, \& Rubenstein, 1978; Winters, Winter, \& Burger, 1978). Furthermore, in the limited developmental comparisons that have been conducted, subjective age of acquisition is one measure that has been found to contribute to recognition performance for spoken words across several age levels (Cirrin, 1984). ${ }^{4}$ Together, these findings suggest that somehow adults have access to information that is relevant to children's word knowledge, and that their ageof-acquisition estimates can be used as a basis for selecting words in developmental studies (i.e., as an alternative to relying on either adult or juvenile frequency norms). In our case, the decision to adopt this approach was related, in part, to structural constraints on the test words (see under Method). Thus, in the present study, we employed adults' age-of-acquisition ratings as an estimate of lexical familiarity (i.e., of subjects' perceptual and/or semantic knowledge of words) and examined its effects on children's and adults' mispronunciation-detection performance.

In Experiment 1, we assessed the influence of lexical familiarity, as well as contextual constraint, on sequential word recognition across developmental level. Children (5- and 8-year-olds) and adults were presented with isolated, intact words and words with mispronunciations in either a first or a second syllable. The words, from three age-of-acquisition categories (early, current, or late), were presented in either a constrained or an unconstrained context (with or without a picture referent). The subjects judged the test items as either "intact" or "mispronounced." In the case of older children and adults, we collected reaction times for these judgments. Of par- ticular interest was how mispronunciation-detection performance at different ages would vary with lexical familiarity (operationally defined on the basis of adults' age-of-acquisition estimates) and whether or not lexical familiarity would be sufficient to support differential attention to word-initial input.

\section{Method}

Subjects. The subjects were 325 -year-olds (mean age $=4$ years, 10 months; range $=3,10-5,10), 32$ 8-year-olds $(8,1 ; 6,7-9,10)$, and 32 young adults. The majority of the children were obtained through local daycares serving a middle-class population in Toronto; the majority of the adults were introductory psychology students, who received course credit for their participation. Other subjects were solicited through on-campus advertisements and paid \$5. All subjects were native speakers of English with no reported history of speech or hearing disorder. Five additional younger subjects were not tested, because they failed to give $7 / 10$ correct responses to the familiarization stimuli.

Stimuli. The 96 test words were drawn from a larger pool of words that had been rated by 17 adult volunteers on a 9-point ageof-acquisition (AOA) scale in the manner described by Carroll and White (1973a). (On this scale, a rating of $1=$ acquired at age 2, $5=$ acquired at age $6,9=$ acquired at age 13 or above.) From these ratings, three categories varying in familiarity were formed, which we refer to as early, current, and late words; the mean AOA ratings (and standard errors) for these categories were 2.22 (.52), $4.58(.65$ ) and $7.02(.60$ ); the overall mean was 4.59 (range $=7.70$ ). (The current category was so labeled, because the AOA ratings suggest that children the age of our youngest subjects might be in the process of learning these words.) The mean frequencies (and standard errors) for the early, current, and late words, according to Kolson's (1960) juvenile frequency count for 590,090 words spoken by kindergarteners in the home and school, were 45.62 (14.46), 9.31 (3.52), and .64 (.14); according to Kučera and Francis's (1967) adult frequency count for $1,000,000$ words, they were 39.19 (14.53), 26.59 (7.27), and 6.31 (1.87). (Frequency values were combined for the singular, plural, and possessive forms of words, with a value of .5 assigned to words not contained in the counts, which was the case for $19 \%, 56 \%$, and $56 \%$ of the early, current, and late words in the juvenile count and $6 \%, 12 \%$, and $38 \%$ of the words in the adult count.

The 32 words in each AOA category were divided into two lists (A and $B$ ). Within each list, there were 8 two- and 8 three-syllable words, and, for each word length, there were equal numbers of words with stop or fricative/affricate target phonetic segments in the word-initial and noninitial positions (the latter position was at the beginning of the second syllable); half of the targets were located in syllables with either primary or secondary stress, and half were in unstressed syllables. The number of stop as opposed to the number of fricative/affricate targets was approximately the same across AOA categories. Two audiotapes were prepared from the lists: on Tape 1, List A items were mispronounced, and List B items were intact; on Tape 2, List A items were intact, and List B items were mispronounced. (Thus, on Tape 1, for example, words from the early category in List B with initial targets served as the controls for the corresponding List A words.) Mispronunciations (MPs) were created by changing the target segment in a word to another stop or fricative/affricate to yield a phonologically legal nonword. Table 1 shows the test words, the mean AOA rating (and standard deviation) for each word, and the change used to produce each MP. Colored pictures to accompany the spoken stimuli (all concrete nouns) were created from illustrations in children's books and pasted on individual $8 \times 5$ in. cards.

The test items were recorded in random order on one channel of each tape by a practised female speaker at approximately 3-sec 
Table 1

Test Words and Mispronunciations

\begin{tabular}{|c|c|c|c|c|c|c|c|c|c|}
\hline List A & $M_{\mathrm{AOA}}$ & $S D$ & OS & MP & List B & $M_{\mathrm{AOA}}$ & $S D$ & & MP \\
\hline \multicolumn{10}{|c|}{ Early } \\
\hline 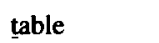 & 1.12 & 0.30 & $t$ & $\mathbf{p}$ & balloon & 1.29 & 0.59 & b & t \\
\hline & & 0.44 & $\mathrm{f}$ & s & & 91 & 0.83 & k & b \\
\hline gen & & 1.08 & b & $\mathbf{k}$ & circ & 2.06 & 0.83 & $\mathbf{s}$ & \\
\hline ira & & 1.23 & $\check{j}$ & $s$ & sandbox & 2.47 & 1.28 & $s$ & \\
\hline 14 & & 0.81 & p & d & $\underline{b}$ & .47 & 0.87 & b & \\
\hline & & 1.74 & f & $\mathrm{v}$ & & 2.64 & 1.17 & $\mathbf{s}$ & \\
\hline & 2. & 1.74 & $\mathrm{~g}$ & $\mathrm{p}$ & & & 1.36 & $t$ & \\
\hline pian & & 1.54 & p & g & to & 2.88 & 1.05 & $t$ & \\
\hline break & 1.65 & 1.11 & $f$ & $\mathrm{~s}$ & bro & 1.65 & 0.49 & $x$ & 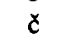 \\
\hline trt & & 0.94 & $\mathrm{t}$ & $\mathbf{g}$ & & & 0.88 & & 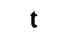 \\
\hline tor & & 1.11 & $\mathbf{p}$ & d & & 94 & 0.83 & & \\
\hline suns & & 0.94 & $\mathbf{s}$ & $\mathbf{v}$ & & 55 & 1.05 & k & 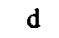 \\
\hline potat & & 0.94 & $\mathrm{t}$ & $\mathbf{b}$ & & & 0.97 & j & \\
\hline ies & 2.2 & 0.92 & b & $\mathbf{k}$ & & & & $g$ & . \\
\hline ed & & 1.12 & $t$ & $\mathbf{k}$ & & & & b & $\mathbf{t}$ \\
\hline Its & & 1.62 & $\check{\mathbf{s}}$ & $\mathbf{v}$ & $\mathrm{ph}$ & 2 & 1.85 & t & p \\
\hline \multicolumn{10}{|c|}{ Current } \\
\hline lack & & 1.01 & b & $\mathbf{g}$ & & 24 & 1.09 & 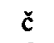 & $\mathbf{v}$ \\
\hline izza & & & p & g & & & & 4 & 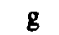 \\
\hline adi & & 2. & s & $\mathrm{v}$ & & & & p & \\
\hline $\mathrm{m}$ & & 1. & $\mathbf{v}$ & 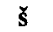 & & & & t & \\
\hline kir & & 1. & b & $t$ & & 4 & 2. & $\mathbf{k}$ & \\
\hline on & & 0. & $\mathbf{p}$ & d & & 2 & 2.65 & $\mathbf{k}$ & \\
\hline tte & & & b & $\mathbf{g}$ & & 2 & 1. & f & \\
\hline facto & & & $f$ & $\mathrm{y}$ & & 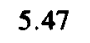 & 1.81 & t & 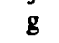 \\
\hline eay & & & $v$ & 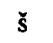 & & & & t & \\
\hline ac] & & & $\check{\mathbf{s}}$ & $v$ & & & & & \\
\hline & & & b & $\mathbf{k}$ & & & & & \\
\hline & & & $\mathbf{k}$ & d & & 76 & 2.28 & j & šs \\
\hline & & & d & $\mathbf{p}$ & & & 1.60 & $t$ & $\mathbf{s}$ \\
\hline & & & j & f & & & & b & $\mathbf{k}$ \\
\hline the & & & $t$ & $\mathbf{b}$ & & & 1.76 & $t$ & b \\
\hline$=$ & & & p & d & $\mathrm{mu}$ & 17 & 1.23 & $z$ & $c$ \\
\hline \multicolumn{10}{|c|}{ Late } \\
\hline Iroe & & & $\mathbf{s}$ & $\mathbf{g}$ & & & 1.03 & 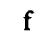 & \\
\hline$o q$ & & & $\mathbf{k}$ & d & & & & $t$ & \\
\hline ya & & & $\mathbf{k}$ & d & & & 1.37 & p & 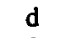 \\
\hline & & & $\mathbf{s}$ & $\mathbf{v}$ & & & & $\mathrm{v}$ & $\theta$ \\
\hline & & & d & $\mathbf{k}$ & 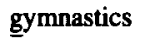 & 0 & 1.17 & j & f \\
\hline ane & 6. & 1.36 & $\mathbf{s}$ & $\mathbf{v}$ & & 53 & 1.70 & $t$ & g \\
\hline ind & & & b & $\mathbf{t}$ & & & & g & \\
\hline avil & & & p & $\mathbf{g}$ & & 2 & 1.18 & p & d \\
\hline cece & & 2. & 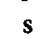 & 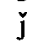 & & 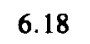 & 1. & $\mathbf{r}$ & $\mathrm{d}$ \\
\hline & & & c & $\mathbf{z}$ & & & & t & \\
\hline & & & $\mathrm{t}$ & b & & & 1. & f & ž \\
\hline & & & p & 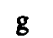 & & 8.29 & 0.77 & $\mathbf{v}$ & $\check{c}$ \\
\hline & & & p & d & & 6.11 & 1.90 & f & $\check{c}$ \\
\hline & & & $\mathbf{k}$ & b & & 6.94 & 0.75 & $\mathbf{p}$ & d \\
\hline & & & f & g & & & 1.32 & b & $\mathbf{k}$ \\
\hline 미 & & 0.94 & d & $\mathbf{k}$ & diploma & 7.71 & 0.85 & $\mathbf{p}$ & $\mathrm{g}$ \\
\hline
\end{tabular}

Note-OS = original segment. MP = segment used to produce the mispronunciation on Tape 1 or 2 . Underscoring indicates the position of the MP in a word.

intervals. An assistant subsequently listened to each tape and located (marked with a fine crayon) the onset of each target segment (intact or mispronounced) by drawing the tape over the playback head and listening to the output via headphones. A second listener checked these judgments. Across the two tapes, there were $18 \%$ disagreements (of less than $5 \mathrm{msec}$ ), which were resolved on the basis of collaborative judgments. A brief tone was then aligned with the onset of each target segment on the second channel of the tape.
The accuracy of tone placement was estimated to be within $5 \mathrm{msec}$. The mean duration of the test words across the two tapes was estimated to be $745 \mathrm{msec}$.

Procedure. Subjects were tested individually, in sessions lasting approximately 30-45 min. Each subject was seated at a table in a quiet room and told that he or she would listen to a list of words, but that some of the words contained mistakes and "were said wrong." The subject was asked to indicate which words were said correctly and which were mispronounced, by pressing one of two buttons on a response box. Depressing one button illuminated a green light and corresponded to an "intact" judgment; depressing the other button illuminated a red light and corresponded to a "mispronounced" judgment. The older children and adults were instructed to rest their preferred hand in the middle of the response box and to make their responses as quickly but as accurately as possible.

The children and adults were randomly assigned to either Tape 1 or Tape 2 in one of two conditions; 16 of the subjects in each age group listened to the tapes while viewing pictures of the words, and 16 did not view the pictures. The test words on each tape were preceded by 5 pairs of practice items (each pair consisting of intact and mispronounced versions of a given word). All stimuli were presented over matched and calibrated Sennheiser HD430 headphones at a comfortable listening level via a portable Uher tape recorder (Model 4200).

During familiarization, the subjects were given feedback by the experimenter concerning their responses. If a subject responded correctly on at least $7 / 10$ trials, then testing began. Each test trial was initiated by the experimenter. In the case of the older children and adults, the tone on the second channel of the tape (inaudible to subjects) triggered a digital timer, which was stopped by the subject's buttonpress. On each trial, the experimenter manually recorded the subject's judgment; reaction times were also recorded from the visual display of the timer. The experimenter then reset the timer and initiated a new trial (including presentation of a picture, if appropriate). No specific feedback (only general encouragement, in the case of children) was given during testing.

\section{Results}

Hits and false alarms. We first calculated each subject's hit rate for initial and noninitial errors at each AOA level and each subject's false alarm rate for matched, intact items (see Table 2). (A response of "mispronounced" to a mispronounced word was scored as a hit; the same response to an intact word was scored as a false alarm). Preliminary analyses revealed that hits increased with age and were equally high for early and current words, but lower for late words. No main effect of position or interactions with this factor were observed. Importantly, children's false alarms increased with AOA, particularly those of young children.

For each age group, we therefore also examined the correlation between the number of subjects who made false alarms in response to each of the 96 intact items (across Tapes 1 and 2) and the AOA ratings for those words, with the correlation between AOA and juvenile frequency partialed out (Pearson's $r=-.67$; in this analysis, estimates for frequency of occurrence per $1,000,000$ words were derived from Kolson's (1960) values for words spoken in the home and school and then converted to Standard Frequency Index logarithmic scale values, as proposed by Carroll, 1970). The resulting partial correlations for young children, older children, and adults were 
Table 2

Mean Hits, False Alarms, $d^{\prime}$ and $\beta$ Scores in Experiment 1

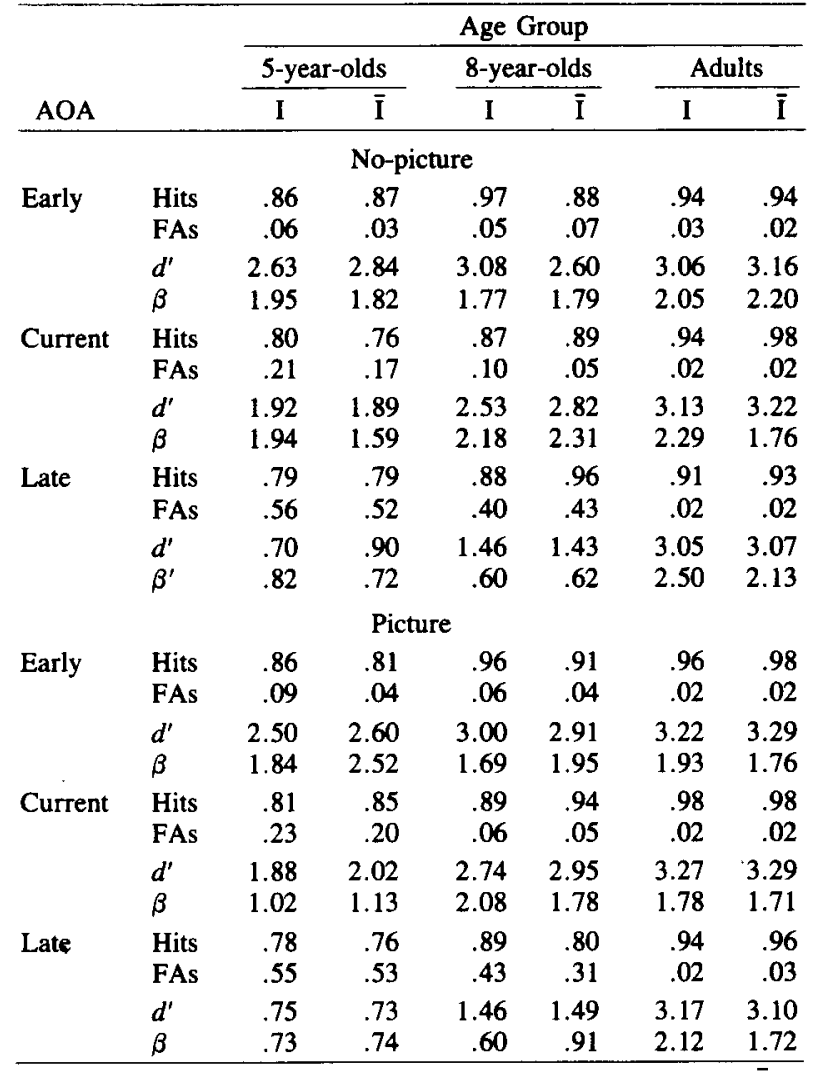

Note-AOA $=$ age of acquisition. $\mathrm{I}=$ initial mispronunciation, $\overline{\mathrm{I}}=$ noninitial mispronunciation. Hits and FAs are in proportions. The highest possible $d^{\prime}$ score was $3.43 ; \beta$ scores could range from .04 to 5.86 .

$.63(p<.01), .52(p<.01)$, and $.09(p>.05)$. In contrast, none of the correlations between the number of subjects making false alarms and frequency, with AOA partialed out, were significant. Virtually identical results were obtained when frequency values from Kučera and Francis (1967) were employed (correlation with AOA = -.35 ). These results are consistent, then, with those of the subject analysis.

MP sensitivity and response bias ( $d^{\prime}$ and $\beta$ ). Although even the children's detections of MPs were quite high, this result was qualified by the age $\times$ AOA interaction observed for false alarms. We therefore used signal detection analysis to derive $d^{\prime}-$ a measure of sensitivity to MPs, separate from $\beta$, response bias. Each subject's hit rate for the eight items in the six cells of the stimulus design ( 3 levels of AOA $\times 2$ levels of position per context condition) and each subject's false alarm rate for the matched, intact items were converted to proportions. Since there was a substantial number of perfect scores (proportions of 1.00 and 0.00 , particularly the former), we replaced such scores and calculated $d^{\prime}$ in the manner recommended by MacMillan and Kaplan (1985). Higher $d^{\prime}$ scores reflect greater discriminability of mispronounced and intact words. $\beta$ scores lower than 1.00 reflect a liberal criterion for making a "mispronounced" response, whereas scores greater than 1.00 reflect a more conservative criterion (i.e., a bias toward responding "intact").

Each subject's $d^{\prime}$ scores were submitted to a 3 (age) $\times 2$ (context) $\times 3$ (AOA) $\times 2$ (position) ANOVA for a mixed design, which revealed main effects of age $[F(2,90)=101.20]$ and $\mathrm{AOA}[F(2,180)=215.87]$, as well as a significant age $\times$ AOA interaction $[F(4,180)=$ 49.26]. (All effects reported here and subsequently were significant at or beyond the level of $\alpha=.05$.) Table 2 shows each age group's mean $d^{\prime}$ scores as a function of context, AOA, and position. Post hoc (Newman-Keuls) comparisons indicated that the young children were more sensitive to MPs in early as opposed to current words and in current as opposed to late words $\left(M_{d^{\prime}}=2.64,1.93\right.$, .77). The older children were more sensitive to MPs in both early and current as opposed to late words ( 2.90 and 2.76 , vs. 1.46). The adults' sensitivity did not differ for early, current, and late words $(3.18,3.22$, and 3.10). Sensitivity to MPs in early words was equivalent across age, but it increased significantly with age for both current and late words (in contrast to false alarms).

Each subject's $\beta$ scores (see also Table 2) were submitted to a 3 (age) $\times 2$ (context) $\times 3(\mathrm{AOA}) \times 2$ (position) ANOVA, which revealed main effects of age $[F(2,90)=8.76]$ and AOA $[F(2,180)=28.37]$ and a significant age $\times$ AOA interaction $[F(4,180)=14.45]$. Post hoc analysis indicated that the young children had a bias toward responding "mispronounced" as AOA increased $\left(M_{\beta}=2.03,1.42, .75\right.$, for eariy, current, and late words). The older children were more biased toward identifying late rather than early and current words as mispronounced (.68 vs. 1.80 and 2.09 ), whereas the adults exhibited no differential biases in their responses to early, current, and late words $(1.98,1.88$, and 2.12$)$. The age comparisons were consistent with these results: Both the young and the older children were more biased than the adults toward identifying late words as mispronounced, and the young children were more biased than either the older children or the adults toward identifying current words as mispronounced; but all the subjects' response criteria for early words were equivalent.

Reaction times for hits. We also examined the older children's and adults' reaction times (RTs) for hits. Each subject's median RTs for detecting initial and noninitial MPs were submitted to separate 2 (age) $\times 2$ (context) $\times 3$ (AOA) ANOVAs (see Table 3, which includes the subjects' miss rates). The analysis for initial hits revealed main effects of age $[F(1,60)=26.10]$ and $A O A$ $[F(2,120)=4.00]$ and a significant context $\times$ AOA interaction $[F(2,120)=3.43]$. The older children detected initial MPs more slowly than did the adults $\left(M_{\mathrm{RT}}=1.456\right.$ vs. $1.100 \mathrm{sec}$ ). Across age, initial MPs were detected faster in early words presented with pictures than in current and late words (1.124 vs. 1.220, and 1.304), but RTs in the no-picture condition did not vary with AOA (1.338, 1.336 , and 1.346, for early, current, and late words); like- 
Table 3

Mean Median Reaction Times for Hits (and Mean Proportions of Misses) in Experiment 1

\begin{tabular}{|c|c|c|c|c|}
\hline \multirow[b]{3}{*}{ AOA } & \multicolumn{4}{|c|}{ Age Group } \\
\hline & \multicolumn{2}{|c|}{ 8-year-olds } & \multicolumn{2}{|c|}{ Adults } \\
\hline & I & $\overline{\mathbf{I}}$ & I & $\overline{\mathbf{I}}$ \\
\hline \multicolumn{5}{|c|}{ No-picture } \\
\hline Early & $\begin{array}{l}1.498 \\
(.03)\end{array}$ & $\begin{array}{l}1.150 \\
(.12)\end{array}$ & $\begin{array}{l}1.178 \\
(.06)\end{array}$ & $\begin{array}{l}.912 \\
(.06)\end{array}$ \\
\hline Current & $\begin{array}{l}1.520 \\
(.13)\end{array}$ & $\begin{array}{l}1.297 \\
(.11)\end{array}$ & $\begin{array}{l}1.151 \\
(.06)\end{array}$ & $\begin{array}{l}.951 \\
(.02)\end{array}$ \\
\hline Late & $\begin{array}{l}1.467 \\
(.12)\end{array}$ & $\begin{array}{l}1.253 \\
(.04)\end{array}$ & $\begin{array}{l}1.225 \\
(.09)\end{array}$ & $\begin{array}{l}.914 \\
(.07)\end{array}$ \\
\hline \multicolumn{5}{|c|}{ Picture } \\
\hline Early & $\begin{array}{l}1.281 \\
(.04)\end{array}$ & $\begin{array}{l}1.157 \\
(.09)\end{array}$ & $\begin{array}{l}.967 \\
(.04)\end{array}$ & $\begin{array}{l}.751 \\
(.02)\end{array}$ \\
\hline Current & $\begin{array}{l}1.442 \\
(.11)\end{array}$ & $\begin{array}{l}1.104 \\
(.06)\end{array}$ & $\begin{array}{l}.999 \\
(.02)\end{array}$ & $\begin{array}{l}.822 \\
(.02)\end{array}$ \\
\hline Late & $\begin{array}{l}1.525 \\
(.11)\end{array}$ & $\begin{array}{l}1.382 \\
(.20)\end{array}$ & $\begin{array}{l}1.083 \\
(.06)\end{array}$ & $\begin{array}{l}.843 \\
(.04)\end{array}$ \\
\hline
\end{tabular}

Note-AOA $=$ age of acquisition. $\mathrm{I}=$ initial mispronunciation, $\overline{\mathrm{I}}=$ noninitial mispronunciation. Reaction times are in seconds and miss rates are shown in parentheses.

wise, the picture versus no-picture comparison was significant for early words, but not for current or late words. Although the three-way interaction was not significant, the advantage for early over current and late words in the picture condition was afforded mainly to the children: (1) the children's RTs for early as opposed to current words were 1.286 versus 1.442 , whereas the adults' RTs were .967 versus .999 ; (2) the children's RTs for current words with and without pictures were more similar ( 1.442 vs. 1.520$)$ than were the adults' (.999 vs. 1.151$)$; and (3) the children's RTs for late words were actually somewhat greater in the picture condition than in the nopicture condition (1.525 vs. 1.467$)$.

The analysis for noninitial hits revealed main effects of age $[F(1,60)=24.07]$ and $A O A[F(2,120)=3.31]$. Again, the children responded more slowly than did the adults $\left(M_{\mathrm{RT}}=1.224 \mathrm{vs}\right.$. .865$)$. There was a trend toward faster MP detections for words with earlier AOA ratings (.992, 1.043, and 1.098, for early, current, and late words), although only the early versus late comparison was significant. The similarity between early and current words appears due mainly to performance for words accompanied by pictures $(.960, .960$, and 1.100 , for early, current, and late words; $1.030,1.120$, and 1.080 for words in the no-picture condition), although the context $\times$ AOA interaction was not significant. (Again, note that the children's RTs were somewhat greater for late words in the picture vs. no-picture condition.)

\section{Discussion}

In the present experiment, although MP detections or hits increased with age and were lowest for late words, additional measures proved more sensitive to both age and AOA and provided a more accurate representation of subjects' abilities at noticing errors in words. First, an age $\times$ AOA interaction for false alarms was observed, such that children, especially younger ones, responded "mispronounced" to intact words with higher AOA ratings (as was also indicated by correlational analyses). This finding suggests that MP detections do not provide a simple measure of recognition; rather, listeners (children, in particular) may use the "mispronounced" response when a word is unfamiliar. Second, the children were indeed more biased, as indexed by $\beta$, toward identifying late words as mispronounced (whether the words contained errors or not). Third, across age, the subjects were equally sensitive, as indexed by $d^{\prime}$, to errors in early words; the young children were less sensitive to errors in current words and less sensitive, in turn, to errors in late words, but this differential sensitivity decreased with age, as overall sensitivity increased. At least this was the case for words that, overall, have a rather low frequency of occurrence, according to both juvenile and adult frequency counts. Consistent with the sensitivity of even young children to these relatively low-frequency words and the developmental trend that we observed, Charles-Luce and Luce (in press) have found evidence for the faster acquisition of low- as opposed to medium- and high-frequency words in their structural analyses of the lexicons of 5- and 7-year-olds. Fourth, not only older children's, but also adults' RTs to detect mispronunciations increased with AOA. Taken together, then, the results of Experiment 1 indicate that, according to several measures, adults' subjective AOA ratings categorically predict age-related differences in performance on the mispronunciationdetection task, or on spoken word recognition more generally; these ratings may thus serve as an estimate of how familiar words that are within a relatively restricted frequency range will be to listeners at different ages, and they may even be superior to estimates based on juvenile or adult frequency counts (see also Carroll \& White, 1973a; Cirrin, 1984; Lachman et al., 1974; Milianti \& Cullinan, 1974; Winters et al., 1978).

Despite the systematic age and AOA variations in performance noted above, the subjects' MP detection hit rates, sensitivity to MPs, and response criteria were all uninfluenced by the position in a word of an error. Even for early words in the picture condition, there was no evidence for differential attention to initial as opposed to noninitial acoustic-phonetic input, according to these measures (see also Cole \& Perfetti's, 1980, results for children). These results conflict with other research involving both children and adults (e.g., Cole, 1973, 1981; Cole et al., 1978; Cole \& Perfetti, 1980; Walley, 1987), a discrepancy that may be due to differences in stimulus materials-specifically, in the stress of the syllable containing a mispronunciation and/or in the position of an error within the syllable (see Note 3). There was, however, some indirect evidence in the RT data for the influence of sequential lexical constraints on recognition. Both older children and adults were especially fast to detect initial errors in early words accompanied by a picture. (There was also some suggestion that whereas the 
children's performance may have benefited the most from greater lexical familiarity and extralexical context, it also suffered the most for late words accompanied by pictures, perhaps because the pictures made relatively unfamiliar words seem more familiar. See the General Discussion.) In contrast, the speed of detecting noninitial errors was influenced only by lexical familiarity, such that responses to both early and current words were very fast. ${ }^{5}$ These results suggest that a first syllable may constrain word identity for listeners, and that given such word-initial information, the influence of additional sources of constraint (lexical familiarity, extralexical context) is reduced (see also Marslen-Wilson, 1987). However, it is unlikely that the present results reflect the on-line use of partial acoustic-phonetic input in recognition; overall, RTs were quite long, and even those of adults were substantially longer than the duration of the stimuli $(745 \mathrm{msec})$. Furthermore, in contrast to Cole and Perfetti's (1980) results, there were no qualitative differences in the patterns of children's and adults' RTs in Experiment 1 that reached significance.

\section{EXPERIMENT 2}

It is possible that the context manipulation (presence or absence of a picture referent) in Experiment 1 was not strong enough to induce differential attention to wordinitial as opposed to noninitial acoustic-phonetic input in our youngest subjects or to reveal developmental differences in this aspect of word recognition. Therefore, in Experiment 2, we examined children's and adults' detections of initial and noninitial errors in words that varied in familiarity and that were presented in constraining or unconstraining sentences.

\section{Method}

Subjects. The subjects were 285 -year-olds (mean age $=4,9$; range $=3,5-5,9), 28$-year-olds $(7,8 ; 6,7-9,9)$, and 28 adults. The subjects were solicited in the same manner as for Experiment 1, and all were native speakers of English with no reported speech or hearing disorder. Two additional younger subjects were not tested, because they failed to give $6 / 8$ correct responses to the familiarization stimuli.

Stimuli. The 96 test words used in Experiment 1 served as the target words for the sentences in Experiment 2. Two carrier sentences (one constraining and one unconstraining) of approximately equal length (mean numbers of words $=9.6$ and 7.8 ) were created for each test word. The same word or a word with a similar wordfinal phonetic segment preceded the target in each sentence pair. Table 4 contains examples of constraining and unconstraining sentence contexts for target words at each AOA level.

The results of Experiment 1 pointed to the importance of assessing children's false alarms in the MP detection task. However, such assessment is problematic in the case of fluent speech, because it may be difficult to determine to what precisely in a sentence a child (or any listener) is responding. Target words were therefore always located sentence-finally in Experiment 2, to allow us to conclude with some certainty that when a subject made a false alarm, it was to the control word, rather than to some other word in the sentence (see also Walley, 1987). We felt as well that the sentence-final location would ensure that children were presented with all of a sen-
Table 4

Examples of Constraining and Unconstraining Sentence Contexts for Target Words at Each Age-of-Acquisition Level

\begin{tabular}{|c|c|c|c|}
\hline $\mathrm{AOA}$ & Context & Carrier Sentence & $\begin{array}{l}\text { Target } \\
\text { Word }\end{array}$ \\
\hline Early & Constraining & $\begin{array}{l}\text { A man who has a badge } \\
\text { and a gun is called a }\end{array}$ & policeman \\
\hline Early & Unconstraining & $\begin{array}{l}\text { One man who sometimes } \\
\text { works at night is a }\end{array}$ & policeman \\
\hline Current & Constraining & $\begin{array}{l}\text { Sherry rode the Ferris } \\
\text { wheel at the }\end{array}$ & carnival \\
\hline Current & Unconstraining & Sherry rode her bike to the & carnival \\
\hline Late & Constraining & $\begin{array}{l}\text { The hunters in the jungle } \\
\text { went on a }\end{array}$ & safari \\
\hline Late & Unconstraining & $\begin{array}{l}\text { It can be dangerous to go } \\
\text { on a }\end{array}$ & safari \\
\hline
\end{tabular}

tence before responding and that they would not fail to respond because they were waiting for the rest of the sentence. Finally, sentence-final location should have provided results comparable to those of Experiment 1 (because words in this position are most similar acoustically to isolated words).

To verify the constraint manipulation, 20 adults participated in a cloze task (see Cole \& Perfetti, 1980). An assistant read the 96 constraining carrier sentences (in different random orders) to 10 of the subjects and the 96 unconstraining carriers to the other 10 subjects, thus omitting the final, target word of each sentence on this first trial. For each sentence, the subject was asked to guess the missing word aloud, and the response was recorded by the assistant. If the subject failed to guess the target, the assistant provided the first (correct) syllable of the word, and the subject made another guess.

After Trial 1 (with no acoustic-phonetic input corresponding to the target), early, current, and late targets were identified for constraining carriers $88 \%, 85 \%$, and $63 \%$ of the time, and for unconstraining carriers $9 \%, 10 \%$, and $2 \%$ of the time. A two-way completely randomized ANOVA for items revealed main effects of context $[F(1,186)=782.02]$ and AOA $[F(2,186)=16.66]$ and a significant context $\times$ AOA interaction $[F(2,186)=4.61]$, such that early and current targets were identified more often than late ones in constraining carriers, whereas these target words were identified equally often in the unconstraining carriers. All constraining versus unconstraining comparisons were significant. Thus, without any acoustic-phonetic information about the targets, the constraining carriers did constrain the adults' productions, although more so for early and current targets than for late ones. After Trial 2 (with the correct first syllable), early, current, and late targets were correctly identified $99 \%, 100 \%$, and $94 \%$ of the time for constraining carriers, and $90 \%, 89 \%$, and $75 \%$ of the time for unconstraining carriers. An ANOVA revealed main effects of context $[F(1,186)=$ $36.54]$ and age $[F(2,186)=9.10]$; targets were identified more often for constraining than for unconstraining carriers, and late targets were identified less often than early and current ones. However, identifications of late targets for constraining carriers appears to have improved substantially over Trial 1 and approached the ceiling level of performance for early and current targets.

Two audiotapes (based on Lists A and B of Experiment 1) were prepared for each context condition (constraining and unconstraining sentences) in a manner similar to that described for Experiment 1 . Across the four tapes, there were $4 \%$ disagreements (of less than $5 \mathrm{msec}$ ) regarding target phoneme onset and these were resolved in a collaborative judgment session. Accuracy of tone location was estimated to be within $5 \mathrm{msec}$. The mean duration of the target words across the four tapes was estimated to be $697 \mathrm{msec}$.

Procedure. Fourteen of the subjects in each age group were randomly assigned to Tape 1 or 2 in the constrained context condi- 
tion, the other 14 to Tape 1 or 2 in the unconstrained context condition. Following several familiarization sentences, the subjects were asked to judge whether any of the words in the test sentences were mispronounced or whether all were said correctly. Otherwise, the procedure was virtually identical to that of Experiment 1.

\section{Results}

Hits and false alarms. Preliminary analyses indicated that both the children's and the adults' hit rates were generally high. Also, the pattern of false alarms was virtually identical to that in Experiment 1 (i.e., younger children were particularly likely to make false alarms as AOA increased), as were the correlations between the numbers of subjects making false alarms in response to intact words and the AOA ratings for the words (with either juvenile or adult frequency partialed out). Accordingly, we again used signal detection analysis to examine the subjects' sensitivity to MPs and their response biases.

MP sensitivity and response bias ( $d^{\prime}$ and $\beta$ ). As in Experiment $1, d^{\prime}$ scores were first calculated for each subject on the basis of hits and false alarms (to intact, matched items) and then submitted to a 3 (age) $\times 2$ (context) $\times$ 3 (AOA) $\times 2$ (position) ANOVA, which revealed main effects of age $[F(2,78)=137.14]$ and AOA $[F(2,156)=$ 217.15], as well as a significant interaction of age $\times$ AOA $[F(4,156)=47.36]$. Table 5 shows each age group's mean $d^{\prime}$ scores as a function of context, AOA, and position, together with the hit and false alarm rate data. Post hoc comparisons indicated that the young children's sensitivity to MPs decreased with increasing AOA $\left(M_{d^{\prime}}=\right.$ $2.38,1.47$, and .34 , for early, current, and late words), as did the older children's $(2.98,2.66,1.32)$, but again the adults' performances did not vary with AOA (3.30, $3.28,3.17$ ). All age comparisons were significant (in contrast to Experiment 1, where performance for early words was equivalent across age).

Each subject's $\beta$ scores were submitted to a 3 (age) $\times$ 2 (context) $\times 3$ (AOA) $\times 2$ (position) ANOVA (see also Table 5), which revealed a main effect of age $[F(2,78)=$ 27.00 ], as well as significant interactions for age $\times \mathrm{AOA}$ $[F(4,156)=6.99]$, age $\times$ position $[F(2,78)=3.34]$, and age $\times$ AOA $\times$ position $[F(4,156)=2.73]$. Post hoc comparisons conducted to examine the nature of the age $\times A O A \times$ position interaction indicated that within each age group, none of the unconfounded initial versus noninitial comparisons were significant, except that the adults were especially biased to identify late words with initial rather than noninitial MPs as mispronounced $\left(M_{\beta}=1.46\right.$ vs. 2.22). We therefore considered the two-way interactions further. Examination of $\beta$ as a function of age and AOA revealed that the young children's scores did not vary with AOA $(1.11, .90$, and 1.00 , for early, current, and late words), nor did the adults' $(1.58,1.68$, and 1.84); in contrast, the older children were particularly likely to respond to late rather than early and current words as mispronounced (.88 vs. 1.64 and 1.70 ). Examination of the age $\times$ position interaction indicated that the young children exhibited a bias toward responding "mispronounced"
Table 5

Mean Hits, False Alarms, $d^{\prime}$ and $\beta$ Scores in Experiment 2

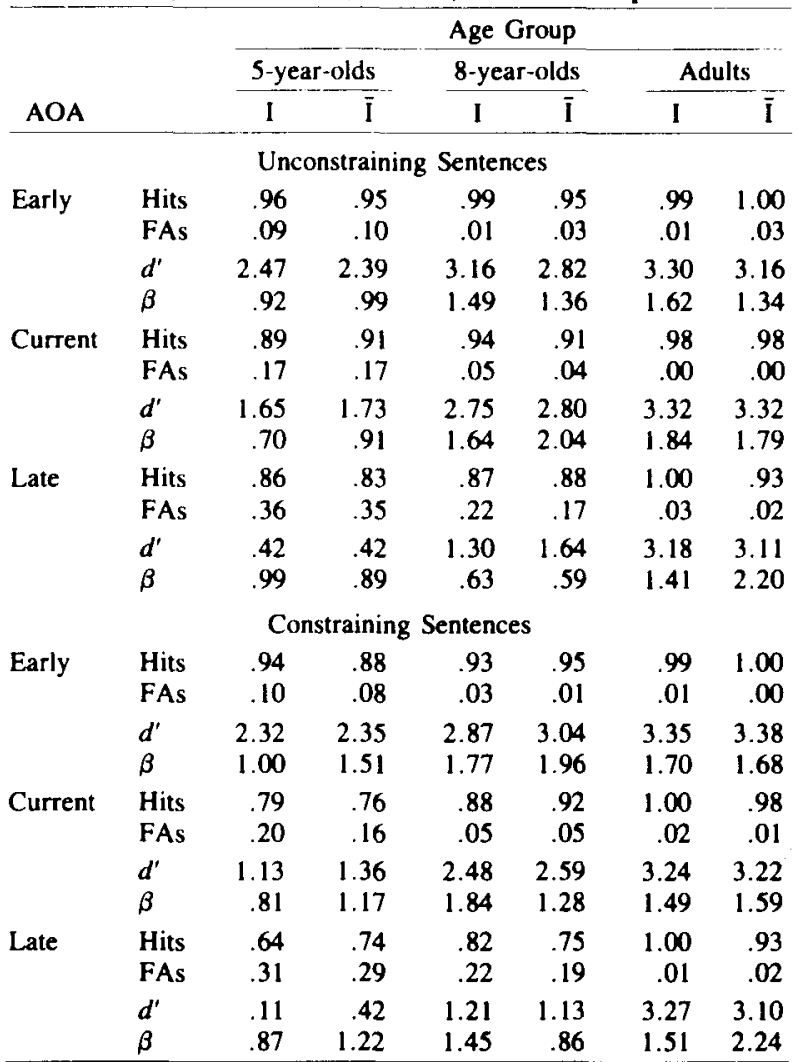

Note-AOA $=$ age of acquisition. $I=$ initial mispronunciation, $\overline{\mathrm{I}}=$ noninitial mispronunciation. Hits and FAs are in proportions. The highest possible $d^{\prime}$ score was $3.43 ; \beta$ scores could range from .04 to 5.86 .

to words with initial rather than noninitial MPs $(M=.88$ vs. 1.12), whereas this comparison was not significant for the older children (1.47 and 1.35) or for adults (1.60 and 1.81). The young children's scores for words with initial MPs were also lower than the older children's and adults'; $\beta$ scores for words with noninitial MPs increased with age.

Reaction times for hits. The older children's and adult's median RTs for detecting initial and noninitial MPs were submitted to separate 2 (age) $\times 2$ (context) $\times 3$ (AOA) ANOVAs (see Table 6, which also shows miss rates). The analysis for initial hits revealed a main effect of age $[F(1,52)=49.16]$ and significant interactions for age $\times$ context $[F(1,52)=5.43]$ and context $\times$ AOA $[F(2,104)=4.49]$. Post hoc comparisons conducted to examine the nature of the age $\times$ context interaction indicated that although the adults tended to detect initial MPs more slowly in the unconstrained than in the constrained context $\left(M_{\mathrm{RT}}=1.001 \mathrm{vs} .881 \mathrm{sec}\right)$, this comparison was not significant; in contrast, the older children were actually faster to detect MPs in the unconstrained rather than the constrained context ( 1.410 vs. 1.698). Both age comparisons were significant. Examination of the context $x$ 
Table 6

Mean Median Reaction Times for Hits (and Mean Proportions of Misses) in Experiment 2

\begin{tabular}{|c|c|c|c|c|}
\hline \multirow[b]{3}{*}{ AOA } & \multicolumn{4}{|c|}{ Age Group } \\
\hline & \multicolumn{2}{|c|}{ 8-year-olds } & \multicolumn{2}{|c|}{ Adults } \\
\hline & I & $\overline{\mathrm{I}}$ & I & $\overline{\mathrm{I}}$ \\
\hline \multicolumn{5}{|c|}{ Unconstraining Sentences } \\
\hline Early & $\begin{array}{l}1.457 \\
(.01)\end{array}$ & $\begin{array}{l}1.195 \\
(.05)\end{array}$ & $\begin{array}{l}1.038 \\
(.01)\end{array}$ & $\begin{array}{l}.731 \\
(.00)\end{array}$ \\
\hline Current & $\begin{array}{l}1.391 \\
(.06)\end{array}$ & $\begin{array}{l}1.292 \\
(.09)\end{array}$ & $\begin{array}{l}.965 \\
(.02)\end{array}$ & $\begin{array}{l}.766 \\
(.02)\end{array}$ \\
\hline Late & $\begin{array}{l}1.382 \\
(.13)\end{array}$ & $\begin{array}{l}1.259 \\
(.12)\end{array}$ & $\begin{array}{l}.999 \\
(.00)\end{array}$ & $\begin{array}{l}.759 \\
(.07)\end{array}$ \\
\hline \multicolumn{5}{|c|}{ Constraining Sentences } \\
\hline Early & $\begin{array}{l}1.493 \\
(.05)\end{array}$ & $\begin{array}{l}1.281 \\
(.07)\end{array}$ & $\begin{array}{r}.860 \\
(.01)\end{array}$ & $\begin{array}{l}.643 \\
(.00)\end{array}$ \\
\hline Current & 1.612 & 1.303 & .844 & .703 \\
\hline & $(.12)$ & $(.08)$ & $(.00)$ & $(.02)$ \\
\hline Late & $\begin{array}{l}1.988 \\
(.18)\end{array}$ & $\begin{array}{l}1.638 \\
(.25)\end{array}$ & $\begin{array}{l}.940 \\
(.00)\end{array}$ & $\begin{array}{l}.670 \\
(.07)\end{array}$ \\
\hline
\end{tabular}

Note $-\mathbf{A O A}=$ age of acquisition. $\mathrm{I}=$ initial mispronunciation, $\overline{\mathrm{I}}=$ noninitial mispronunciation. Reaction times are in seconds and miss rates are shown in parentheses.

AOA interaction indicated that RTs to errors in early, current, and late words did not differ significantly in the unconstrained context $(1.248,1.178$, and 1.191); however, in the constrained context, RTs to errors in late words were longer than those to errors in early and current words (1.464 vs. 1.177 and 1.228), and RTs were longer to errors in late constrained rather than late unconstrained words. These effects were due mainly to the children's performance (as is evident from their generally higher RTs in the constrained than in the unconstrained context), although the 3-way age $\times$ context $\times$ AOA interaction was not significant.

The analysis for noninitial hits (see also Table 6) did reveal a significant age $\times$ context $\times$ AOA interaction $[F(2,104)=4.45]$, as well as significant age $\times \mathrm{AOA}$ $[F(2,104)=4.39]$ and context $\times \mathrm{AOA}[F(2,104)=3.61]$ interactions. There were main effects of age $[F(1,52)=$ $42.42]$ and AOA $[F(2,104)=6.03]$. Similar to the pattern of results for initial hits, the children responded more slowly to noninitial MPs in late, constrained words than did the adults $\left(M_{\mathrm{RT}}=1.638 \mathrm{vs} . .759\right)$, and more slowly to these errors than to those in either late, unconstrained words (1.638 vs. 1.259$)$ or current, constrained words (1.638 vs. 1.303). No other unconfounded comparisons were significant.

\section{Discussion}

As in Experiment 1, we found systematic age- and AOA-related variations in sensitivity to MPs. However, the observed pattern of response biases was somewhat different, in that only the older children (not the young children) were biased toward identifying late words as mispronounced, perhaps because it was only these words that were not very well known to them. In contrast, the sentences (whether constraining or unconstraining) may have discouraged the young children, who knew relatively fewer of the words, from making a "mispronounced" response. (For example, the more discourse-like context may have prompted the young children to expect that more of the words were correct, even though they did not actually know them.) The adults presumably knew all of the words quite well. However, the older children were quite slow at detecting word-initial MPs, particularly in constraining sentences, whereas the adults showed at least a trend toward faster detections in constraining than in unconstraining sentences. Furthermore, it was primarily the children's responses to initial errors that were slow for late words in constraining sentences, an effect which became more apparent for the detection of noninitial errors. (A similar trend was noted in Experiment 1.) The constraining context may have made what were to the children relatively unfamiliar words seem more familiar and thereby slowed their responses; in contrast, the children responded "mispronounced" quickly to late words in the unconstraining context, not because they recognized the words, but often because the words were unfamiliar (witness their false alarm rates). These results do not necessarily conflict, then, with previous studies in which various types of constraining contexts have been found to facilitate children's responses to relatively more familiar words (Cole \& Perfetti, 1980; Goodman \& Huttenlocher, 1987; Perfetti, Goldman, \& Hogaboam, 1979; Schvaneveldt, Ackerman, \& Semlear, 1977; Stanovich, 1981; Tyler \& Marslen-Wilson, 1981).

We again found little evidence for more detections of or greater sensitivity to word-initial as opposed to noninitial MPs, even for early words presented in constraining sentences. However, the young children were particularly biased toward identifying words with initial rather than noninitial errors as mispronounced, regardless of AOA level; the adults exhibited a similar positional bias, but only for late words. The older children's and adults' RTs for detecting initial and noninitial errors were also influenced to a different extent by lexical familiarity and extralexical context. Given an incorrect first syllable, the children's responses were slower in context across AOA, and the subjects' responses, across age, were slower for late words in context; in contrast, given a correct first syllable, only the children's responses to late words in constraining sentences were very slow. ${ }^{6}$ Thus, the influence of lexical familiarity and extralexical context on the detection of noninitial as opposed to initial errors was reduced more in the case of adults' responses than in children's-a pattern of results that points to developmental increases in sequential lexical constraints on recognition. Again however, it should be noted that the subjects' responses were generally longer than the duration of the stimuli $(697 \mathrm{msec})$ and thus presumably do not reflect the on-line use of acoustic-phonetic information in recognition.

\section{GENERAL DISCUSSION}

The most conspicuous finding in the present study was the variation in subjects" performance, according to 
several measures, with adults' subjective AOA estimates. Although lexical familiarity was pre-experimentally defined on the basis of these ratings, certainly familiarity is not an inherent characteristic of words (see also Chi, 1977; Grosjean, 1985), but rather one that also reflects listener characteristics. Consistent with this view, we observed age $\times$ AOA interactions, or the growth of lexical familiarity with age, in subjects' false alarms, sensitivity, and response biases toward MPs, as well as in their RTs. These results extend those of Cirrin (1984), who found that AOA contributes to lexical decision times for spoken words $\left(M_{\mathrm{AOA}}=3.21\right.$, range $=5.35$, according to Carroll and White's [1973a] AOA scale) in children as young as 6 years of age, to several dependent measures in a different task, to a wider stimulus AOA range, and to a slightly younger age group (see also Gilhooly \& Gilhooly, 1980; Lyons et al., 1978; Winters et al., 1978). In their review of the effects of AOA on adult word recognition and production, Gilhooly and Watson (1981) conclude that such effects are only apparent in tasks where words must be overtly produced in response to cues, not simply recognized. Our results do not contradict this conclusion to the extent that the MP detection task may involve not only pattern recognition (finding a word in memory that is similar to a test item), but also the production of a response that is based on the outcome of a fairly explicit similarity comparison.

The relation we observed between subjective AOA estimates and performance in the MP detection task also points to the validity of using these estimates as an index of lexical familiarity for listeners of different ages. That is, when adults say that they learned a given word at a certain age, then children at that age are likely to know the word and all subjects are likely to know it better than a word with a later AOA rating. The practical implication of this relation, then, is that these estimates can serve as a basis for selecting materials for developmental investigations and, thus, as an alternative both to the sort of norm-based measures described earlier and to prior empirical determinations of familiarity (e.g., Elliott et al., 1979). This approach may be advantageous when, for example, the test items of interest are from a restricted frequency range, or when normative information about the words is not available.

At a theoretical level, it is not entirely clear what underlies adults' AOA estimates or why these subjective estimates should accurately reflect children's or their own lexical knowledge. Previously, it has been suggested that AOA estimates may reflect residence time of lexical items in memory and thus, for example, the cumulative or lifespan experienced frequency of words (e.g., Carroll $\&$ White, 1973a; Cirrin, 1984). However, the cumulative experienced frequency account, according to which a multiplicative function of frequency and AOA might be expected to be a better predictor of performance than either variable alone, has not been supported in studies of picture naming and word completion by adults (Carroll \& White, 1973b; Gilhooly \& Gilhooly, 1979). As Gilhooly
(1984) points out, length of residence might be important in other ways, such as by allowing implicit priming effects or lifespan frequency-of-production effects to develop, but assessment of these alternate hypotheses is complicated by the fact that actual AOA and length of residence for words are perfectly correlated for any individual. Therefore, Gilhooly conducted a study in which 20- to 58-year-olds were visually presented with words that varied in their recency of introduction into English, such that AOA or residence time varied with subject age, as the other factor remained relatively constant. AOA (based on subjective estimates, the validity of which were confirmed), not length of residence, proved to be the more important factor for predicting the speed of word naming. Thus, subjective AOA estimates may somehow reflect age of acquisition per se. This is not to suggest that adults possess literal, autobiographical information concerning their own language-learning histories (information about the actual age at which they acquired particular words), but that their estimates are nevertheless substantially influenced by the relative AOA of words during development, perhaps because early learned words are somehow better consolidated than later ones (Carroll \& White, 1973b; Gilhooly, 1984). (Consistent with this, we found performance in the MP detection task to be best and most similar across age for words with early AOA ratings, even though for adults there has presumably been greater opportunity for the development of priming, experienced frequency, or lifespan production effects). It is also possible that AOA estimates reflect explicit knowledge (or metalexical knowledge) on the part of adults as to what are "age-appropriate" words or what words children are likely to be learning at various ages (see also Gilhooly \& Watson, 1981)-knowledge that is in accord with their own experience for many words. As a step toward further illumination of the basis for subjective AOA estimates, information concerning whether or not children could themselves make AOA estimates would be useful, as well as information about how such estimates change with age and/or experience and how they relate to children's own performance in word-recognition tasks. In addition, future research might seek to differentiate between the perceptual/structural and semantic aspects of children's and adults' lexical knowledge that are tapped by subjective measures-for example, by varying instructions for making AOA estimates, task comparisons, and so forth. ${ }^{7}$

In the present study, hit rates did not prove to be a very sensitive measure of children's mispronunciation detections and thus of recognition for words varying in familiarity; rather, this measure was qualified by the false alarm data. Although the importance of employing intact controls may seem obvious, not much attention has in fact been given to false alarms or other errors in previous implementations of the mispronunciation-detection task. Given an assessment of false alarms however, this task would seem to constitute a valid paradigm for studying word recognition, and it is one that children generally un- 
derstand quite well and enjoy performing. It also has considerable "ecological validity," inasmuch as listeners, including children, do encounter production errors, for which they are often expected to compensate, in the course of listening to speech, and it is therefore important to know what factors influence their ability to do so. More interesting theoretically was the children's tendency in the present study to respond "mispronounced" to unfamiliar, mispronounced, and intact words, given that they did have the opportunity to label such items as intact. Such a result would have been consistent with Cole and Perfetti's (1980) suggestion that in learning a language, children may tolerate (or actively ignore) unfamiliar words in order to prevent disruptions in the comprehension process and therefore often fail to detect mispronunciations, especially in unconstraining or unpredictable contexts. However, in their study (see also Cole, 1981), children did not make overt "correct" (intact) responses, only "mispronounced" ones. In comparison, our version of the task seems to have encouraged children to make "mispronounced" responses for unfamiliar words; apparently, they were unwilling to explicitly maintain that these words were correct. Their responses might then reflect the knowledge that certain words were indeed unfamiliar (see also Anderson \& Freebody, 1981; Wellman, 1977)-knowledge that is important if such words are to be assimilated into one's vocabulary and that appears to be a developmentally primary component of comprehension monitoring (e.g., see Baker, 1985a). Alternatively, children's high rate of mispronounced responses for unfamiliar words might reflect the (incorrect) conviction that they actually knew these words, but that the words were mispronounced; this would be consistent with observations that children are overconfident about their identification responses (e.g., Elliot et al., 1987; see also Walley, 1988), which may be yet another strategy children use to avoid disruptions in the comprehension process. These two accounts could be evaluated by asking children to give explicit judgments about whether or not they know mispronounced and intact words varying in AOA.

A major expectation in the present study had been to observe age-related increases in sequential constraints on spoken word recognition. However, neither hits nor $d^{\prime}$ varied substantially with the position in a word of an error, and the position factor did not interact with age, AOA, and/or context in the manner expected. Perhaps this was because there was no real time pressure on subjects to identify words and make a response. Or perhaps the test words (from a restricted, low frequency range) were not familiar enough to support primary reliance on wordinitial input for recognition. One argument against the latter account is that all subjects did (according to one or more of the dependent measures employed) respond differentially to the AOA categories. Furthermore, in Experiment 2, adults exhibited a greater bias toward responding "mispronounced" to initial rather than noninitial MPs in late words (see also Samuel, 1981); they appear to have devoted greater attention to the least constrained parts of the words that, according to other adults' AOA estimates and to the empirical data from children in the present study, should have been least familiar. In contrast, young children's response criterion was influenced only by positional information; older children's, only by lexical familiarity. Perhaps because the young children encountered a substantial proportion of unfamiliar words, they attended to and anticipated errors at the beginnings of all words. (Put another way, the beginnings of even familiar words may not be very constraining in such a highuncertainty context.) The older children may have been especially concerned with detecting any errors in the smaller proportion of words that were unfamiliar to them.

We also observed evidence for differential responding to word-initial and noninitial information in the RT results of both experiments. Furthermore, lexical context (a correct first syllable), as well as sentence context, appeared to exert greater constraints on adults' responses than children's, such that the influence of other potential sources of constraint was reduced (see also Marslen-Wilson, 1987). Thus, children's detections of both initial and noninitial MPs in late words presented in constraining sentences were slow. It was suggested that these sentences may have made what were to children relatively unfamiliar words (ones to which they would otherwise have quickly responded "mispronounced," without having actually recognized the intended words) seem more familiar and thus slowed their responses. (This explanation is consistent with the two-step assumption of the task-namely, that in order to detect an error, the listener first finds a word in his or her lexicon that is roughly similar to the input and then notes the discrepancy. Indeed, RTs for detecting errors were generally longer than those for correctly identifying words as intact.) The observation of more dramatic developmental changes in sequential word recognition may depend on achieving more rigorous control over the acoustic-phonetic input that is available to listeners at any given point during the recognition process. Although this might be accomplished in valid, on-line implementations of the present task, the gating paradigm (see Grosjean, 1980), in which listeners are presented only with partial acoustic-phonetic information about words, may be particularly well suited for such developmental investigations (see, e.g., Elliott et al., 1987; Walley, 1988).

\section{REFERENCES}

Anderson, R. C., \& Freebody, P. (1981). Vocabulary knowledge. In J. T. Guthrie (Ed.), Comprehension and teaching (pp. 77-117). Newark, DE: International Reading Association.

BAgLeY, W. C. (1900). The apperception of the spoken sentence: A study in the psychology of language. American Journal of Psychology, 12, 80-130.

BAKER, L. (1985a). How do we know when we don't understand? Standards for evaluating text comprehension. In D. L. Forrest, G. E. MacKinnon, \& T. G. Waller (Eds.), Metacognition, cognition, and human performance (pp. 155-205). New York: Academic Press. 
BAKER, L. (1985b, April). When will children acknowledge word comprehension failures? Paper presented at the Biennial Meeting of the Society for Research in Child Development, Toronto.

Carroll, J. B. (1970). An alternative to Juilland's usage coefficient for lexical frequencies, and a proposal for a Standard Frequency Index. Computer Studies in Humanities \& Verbal Behavior, 3, 61-65.

Carroll, J. B. (1971). Measurement properties of subjective magnitude estimates of word frequency. Joumal of Verbal Leaming \& Verbal Behavior, 10, 722-729.

Carroll, J. B., Davies, P., \& Richman, B. (1971). The American Heritage word frequency book. New York: Houghton Mifflin.

Carroll, J. B., White, M. (1973a). Age of acquisition norms for 220 picturable nouns. Journal of Verbal Leaming \& Verbal Behavior, 12, 563-576.

Carroll, J. B., \& White, M. (1973b). Word frequency and age of acquisition as determiners of picture-naming latency. Quanterly Journal of Experimental Psychology, 25, 85-95

Charles-LuCe, J., \& Luce, P. A. (in press). Similarity neighborhoods of words in young children's lexicons. Journal of Child Language.

CHI, M. T. H. (1977). Age differences in memory span. Joumal of Experimental Child Psychology, 23, 266-281.

Cirrin, F. M. (1983). Lexical access in children and adults. Developmental Psychology, 19, 452-460.

Cirrin, F. M. (1984). Lexical search speed in children and adults. Journal of Experimental Child Psychology, 37, 158-175.

CoLE, R. A. (1973). Listening for mispronunciations: A measure of what we hear during speech. Perception \& Psychophysics, 13, 153-156.

COLE, R. A. (1981). Perception of fluent speech by children and adults. Annals of the New York Academy of Sciences, 379, 92-109.

COLE, R. A., \& JAKIMIK, J. (1978). How are syllables used to recognize words? Joumal of the Acoustical Society of America, 67, 965-970.

COLE, R. A., JAKIMIK, J. (1980). A model of speech perception. In R. A. Cole (Ed.), Perception and production of fluent speech (pp. 133163). Hillsdale, NJ: Erlbaum.

Cole, R. A., JAkImik, J., CoOper, W. E. (1978). Perceptibility of phonetic features in fluent speech. Journal of the Acoustical Society of America, 64, 44-56.

Cole, R. A., JAKIMIK, J., a COOPER, W. E. (1980). Segmenting speech into words. Journal of the Acoustical Society of America, 67, 1323-1332.

Cole, R. A., \&erfetti, C. A. (1980). Listening for mispronunciations in a children's story: The use of context by children and adults. Journal of Verbal Learning \& Verbal Behavior, 19, 297-315.

DAle, E., \& ChAll, J. S. (1948). A formula for predicting readability: Instructions. Educational Research Bulletin, 27, 37-54.

DUNLAP, G. (1980). Accessing lexical memory: The role of word meanings and word frequency. Unpublished doctoral dissertation, University of lowa.

Ellott, L. L., Connors, S., Kille, E., Levin, S., Ball, K., \& KATZ, D. (1979). Children's understanding of monosyllabic nouns in quiet and in noise. Journal of the Acoustical Society of America, 66, $12-21$.

Elliott, L. L., Hammer, M. A., Evan, K. E. (1987). Perception of gated, highly familiar spoken monosyllabic nouns by children, teenagers, and older adults. Perception \& Psychophysics, 42, 150-157.

EUKEL, B. (1980). A phonotactic basis for word frequency effects: Implications for automatic speech recognition. Joumal of the Acoustical Society of America, 68. (Abstract No. S33)

GIBSON, E. J., LEVIN, H. (1975). The psychology of reading. Cambridge, MA: MIT Press.

Gilhooly, K. J. (1984). Word age-of-acquisition and residence time in lexical memory as factors in word naming. Current Psychological Research \& Reviews, 3, 24-31.

Gilhooly, K. J., \& Gilhooly, M. L. (1979). Age-of-acquisition effects in lexical and episodic memory tasks. Memory \& Cognition, 7, 214-223.

GiLhooly, K. J., \& Gilhooly, M. L. M. (1980). The validity of ageof-acquisition ratings. British Journal of Psychology, 71, 105-110.

GiLHOOLY, K. J., \& LoGIE, R. H. (1981). Word age-of-acquisition, read- ing latencies and auditory recognition. Current Psychological Research, 1, 251-262.

Gilhooly, K. J., \& WATSON, F. L. (1981). Word age-of-acquisition effects: A review. Current Psychological Reviews, 1, 269-286.

Goodman, J. C., Hutten locher, J. (1987, April). Children's recognition of spoken words. Paper presented at the Biennial Meeting of the Society for Research in Child Development, Baltimore.

Grosjean, F. (1980). Spoken word recognition processes and the gating paradigm. Perception \& Psychophysics, 28, 267-283.

GROSJEAN, F. (1985). The recognition of words after their acoustic offset: Evidence and implications. Perception \& Psychophysics, 38, 299-310.

JAXIMIK, J. (1980). The interaction of sound and knowledge in word recognition from fluent speech. Unpublished doctoral dissertation, Carnegie-Mellon University.

Kolson, C. (1960). The vocabularies of kindergarten children. Pittsburgh: University of Pittsburgh Press.

KuČERA, H., Francis, W. (1967). Computational analysis of presentday American English. Providence, RI: Brown University Press.

Lachman, R., SChafFer, J., \& Hennrikus, D. (1974). Language and cognition: Effects of stimulus codability, name-word frequency, and age of acquisition on lexical reaction time. Journal of Verbal Learning \& Verbal Behavior, 23, 613-625.

LofTes, E., Suppes, P. (1972). Structural variables that determine the speed of retrieving words from long-term memory. Journal of Verbal Learning \& Verbal Behavior, 11, 770-777.

LUCE, P. A. (1986). Neighborhoods of words in the mental lexicon. Research on speech perception (Tech. Rep. No. 6). Indiana University, Bloomington, Department of Psychology, Speech Research Laboratory.

Lyons, A. W., Teer, P., Rubenstein, H. (1978). Age-at-acquisition and word recognition. Journal of Psycholinguistic Research, 7, 179-187.

MacMillan, N. A., \& KAPlan, H. L. (1985). Detection theory analysis of group data: Estimating sensitivity from average hit and falsealarm rates. Psychological Bulletin, 98, 185-199.

MARSLEN-WILSON, W. D. (1984). Function and process in spoken word recognition: A tutorial review. In H. Bouma \& D. G. Bouwhuis (Eds.), Attention and performance X: Control of language processes (pp. 125150). Hillsdale, NJ: Erlbaum.

MARSLEN-WILSON, W. D. (1987). Functional parallelism in spoken word recognition. In U. H. Frauenfelder \& L. Komisarjevsky Tyler (Eds.), Spoken word recognition (pp. 71-102). Cambridge, MA: MIT Press.

MARSLEN-WILSON, W. D., W WeLSH, A. (1978). Processing interactions and lexical access during word recognition in continuous speech. Cognitive Psychology, 10, 29-63.

Milianti, F. I., Cullinan, W. L. (1974). Effects of age and word frequency on object recognition and naming in children. Joumal of Speech \& Hearing Research, 17, 373-385.

Miller, G. A. (1977). Spontaneous apprentices. New York: Seabury Press.

Noотввоом, S. D. (1981). Lexical retrieval from fragments of spoken words: Beginnings versus endings. Joumal of Phonetics, 9, 407-424.

Perfetti, C. A., Goldman, S. R., \& Hogaboam, T. W. (1979). Reading skill and the identification of words in discourse context. Memory \& Cognition, 7, 273-282.

PISONI, D. B., LuCE, P. A. (1987). Acoustic-phonetic representations in word recognition. In U. H. Frauenfelder \& L. Komisarjevsky Tyler (Eds.), Spoken word recognition (pp. 21-52). Cambridge, MA: MIT Press.

RINSLAND, H. D. (1945). A basic vocabulary of elementary school children. New York: Macmillan.

Rubis, D. C. (1980). 51 properties of 125 words: A unit analysis of verbal behavior. Joumal of Verbal Leaming \& Behavior, 19, 736-755.

SAlAsoo, A., PISONI, D. B. (1985). Interaction of knowledge sources in spoken word identification. Joumal of Memory \& Language, 24, 210-231.

SAMUEL, A. G. (1981). Phonemic restoration: Insights from a new methodology. Journal of Experimental Psychology: General, 110, 474-494.

Schyaneveldt, R., Ackerman, B. P., \& Semlear, T. (1977). The 
effect of context on children's word recognition. Child Development, 48, 612-616.

SмIтH, M. E. (1926). An investigation of the development of the sentence and the extent of vocabulary in young children. University of Iowa Studies, 3(5).

Smith, M. K. (1941). Measurement of the size of general English vocabulary through the elementary grades and high school. Genetic Psychology Monographs, 24, 311-345.

Stanovich, K. E. (1981). Attentional and automatic context effects in reading. In C. A. Perfetti \& A. M. Lesgold (Eds.), Interactive processes in reading. Hillsdale, NJ: Erlbaum.

THORNDIKE, E. L., \& LoRGE, I. (1944). The teacher's word book of 30,000 words. New York: Teacher's College Press, Columbia University.

TYLER, L. K., \& MARSLEN-WILSON, W. D. (1976). Some developmental aspects of sentence processing and memory. Journal of Child Language, 5, 113-129.

TYLER, L. K., \& MARSLEN-WILson, W. D. (1981). Children's processing of spoken language. Journal of Verbal Learning \& Verbal Behavior, 20, 400-416.

W ALLEY, A. C. (1987). Young children's detections of word-initial and -final mispronunciations in constrained and unconstrained contexts. Cognitive Development, 2, 145-167.

WALLEY, A. C. (1988). Spoken word recognition by young children and adults. Cognitive Development, 3, 137-165.

Wellman, H. M. (1977). Tip of the tongue and feeling of knowing experiences: A developmental study of memory monitoring. Child Development, 48, 13-21.

Winters, J. J., JR., WinTER, L., \& Burger, A. L. (1978). Confidence in age-of-acquisition estimates and its relationship to children's labeling performance. Bulletin of the Psychonomic Society, 12, 361-364.

\section{NOTES}

1. Thus, in a familiarization session of his study of 4- and 5-yearolds' mispronunciation detections, Cole (1981) presented children with passages containing to-be-mispronounced words; this was done in order to ensure that even if children did not know the test words (i.e., they had not heard the words pre-experimentally and/or did not know their meanings), they would nevertheless be familiar with the correct forms of the words.

2. It is not immediately clear how or whether the measurement problem might be solved: On the one hand, measurement from stimulus offset for words with either initial or noninitial errors might not be sensitive to actual differences in processing speed; measurement from stimulus onset, on the other hand, would presumably put detections of noninitial errors at a disadvantage and likely result in no reaction time difference also. However, additional stimulus manipulations in the standard version of the task can preclude interpretative problems. For example, Cole (1973) found that although adults' detections of both second- and thirdsyllable errors were faster than first-syllable detections, detections of errors at the ends of words were no faster than in the middles of words; reaction times did not simply decrease, the later in a word an error occurred (or the later in a word reaction time measurement began). As another example, Cole, Jakimik, and Cooper (1980) found that reaction times were faster for detecting second-syllable rather than first-syllable errors, especially when the second syllable was in the same word as the first syllable (e.g., cargo vs. car go, both mispronounced as carko).
However, without examination of absolute reaction times relative to stimulus durations, such results do not necessarily support claims concerning on-line sequential recognition.

3. It should also be noted that, in their study, word-initial and secondsyllable mispronunciations were always located in stressed syllables, whereas the stress of syllables containing errors does not appear to have been controlled in Cole's (1981) study, nor was it in Walley's (1987). Yet previous research has shown that although adults detect errors in stressed syllables equally accurately across position and more accurately than in unstressed syllables, positional effects do obtain in adults' reaction times, regardless of the stress of the syllable containing a mispronunciation (Cole \& Jakimik, 1978). Also, in Walley's (1987) study, the superior detection of word-initial as opposed to word-final errors does not appear to have been the simple result of any stress confound, because the position effect was largest for one-syllable words. Furthermore, as MarslenWilson and Welsh (1978, p. 41) point out, syllabic stress effects do not invalidate claims concerning lexical constraint; to the extent that "syllabic stress location generally coincides with the informationally critical part of a word, then it follows directly that mispronunciations in stressed [first and second] syllables should be more detectable," and "it is perhaps no accident that very few tri-syllabic words in the language do have primary stress on the third syllable." Finally, although in Walley's study (and apparently in Cole's 1981 study), noninitial mispronunciations were located at the end, rather than at the beginning, of a syllable and may, therefore, have been less salient than word- and syllable-initial mispronunciations (Cole et al., 1978; Nooteboom, 1981), the detectability of noninitial errors was not simply less than that of initial errors; it was influenced by word length, and thus presumably by lexical constraint.

4. Cirrin found that adults' age-of-acquisition estimates were significant predictors of kindergarteners', first-graders' and adults' lexical decision latencies for auditorily presented words. In a previous study, this measure did not contribute significantly to children's repetition-naming latencies for spoken words (Cirrin, 1983); however, Cirrin notes that values from the Rinsland (1945) juvenile frequency count, which reflect when certain words are acquired or mastered chronologically and which did predict children's naming latencies, were highly correlated with adults' age-of-acquisition estimates, and, that the two measures may not exhibit a large amount of independent variation.

5. Similarly, in subsidiary analyses, we found that RTs for correct rejections of intact early and current words with noninitial targets were equally fast, whereas RTs for intact words with initial targets increased for each AOA level.

6. The speed of the children's correct rejections of intact words with initial targets increased with AOA, and, across age, identifications of late words in context were particularly slow; but only the children's correct rejections of late words (across context) with noninitial targets were slow. Nevertheless, given a (correct) first syllable, the children's correct rejections of current words with noninitial targets were more similar to early words.

7. For example, Eukel (1980) found that adults could make frequency estimates for spoken nonwords and that these estimates were in substantial agreement with objective measures of distance from English. This finding indicates that subjective measures for words may be based in part on phonotactic properties of words, as well as such factors as experienced frequency.

(Manuscript received June 9, 1988; revision accepted for publication September 25, 1989.) 